\title{
Bibliographic databases in psychiatry: an overview
}

\author{
Alexander J. Mitchell, Clare Martin and Ian Preston
}

Literature searching has been revolutionised by the desktop computer. Today it is almost inconceivable to be without the tools to efficiently and comprehensively examine the medical literature. However, as this biomedical literature grows ever more vast, researchers and clinicians need to know which of the many biomedical and psychiatric databases will best cover their particular area of interest. No databases can cover everything. It is necessary to select the most appropriate source of information for the task at hand and for a literature review this will usually entail the use of multiple methods of data collection. In this brief review databases of particular interest to psychiatrists are discussed ${ }^{1}$.

\section{Medline (National Library of Medicine)}

Medline is the electronic derivative of Index Medicus and contains over eight million records. However, it does not include conference abstracts, theses or book chapters and it underemphasises non-English language work. Medline utilises a structured list of 17500 hierarchical medical subject headings (MeSH) to aid searching. Unfortunately, these headings often do not conform to accepted standards (Wakeford \& Roberts, 1993) and searching with MeSH terms alone can be problematic. It provides good value for money for those interested in a single database encompassing all medical specialties. Medline is widely available on-line and can be used on several internet sites on a pay per reference basis.

\section{Embase (Elsevier)}

Embase is a smaller biomedical database of about three million records and there is about a $40 \%$ overlap in coverage between it and Medline. Embase is more up-to-date, has a European slant and is more comprehensive on drug

${ }^{1}$ Products not supplied for review: Embase $\mathrm{CD}$ Neurosciences (Elsevier), Conference Proceedings on CD-ROM (Elsevier), and Geriatric Psychiatry CD (American Psychiatric Press). literature and alternative therapies. The indexing system employs the Emtree thesaurus of almost 40000 medical terms. This provides excellent subject index search capabilities which complement the databases' thorough coverage of psychiatric literature. Academic institutions can subscribe to Embase via BIDS (Bath Information and Data Service). Embase Psychiatry is a subset of Embase. This is a ten-year file with over 303000 citations, most of which contain abstracts. Overall, Embase Psychiatry is the most comprehensive specialised CD-ROM database of psychiatric literature which is restricted only by its limitation to references published after 1986.

\section{PsycINFO/PsycLIT/ClinPSYC (American Psychological Association)}

PsycINFO, derived from Psychological Abstracts, is subdivided into PsycLIT and ClinPSYC. PsycINFO (from 1967), the parent database, covers conference reports, case studies and book chapters. PsycLIT (from 1974) omits dissertations, foreign language books or technical reports. ClinPSYC (from 1980) covers only references with clinical or medical relevance and excludes books and dissertations. Although ClinPSYC starts five years earlier than Embase Psychiatry, they contain roughly the same number of records and both are updated quarterly. There seems little justification for the APA to charge over double the cost of Embase Psychiatry for their product. The indexing system behind PsycINFO is a vocabulary of 4000 terms which is generally superior to Medline but inferior to Embase Psychiatry. As expected, these products very much emphasize psychological topics and as such are not realistic alternatives to (but may complement) primary psychiatric or general medical databases.

\section{Neuroscience Citation Index (Institute for Scientific Information)}

This bibliographic CD-ROM covers neurology, psychiatry, psychopharmacology, neurosurgery, behavioural neurology and developmental neurobiology. It is a five-year database with over 
75000 source items included per year. It covers conference proceedings and book chapters as well as journals. The ISI's citation indexes record all cited references in each article, enabling the researcher to search by citation. For anyone interested in biological psychiatry, this is a valuable acquisition.

\section{Full text databases}

The American Psychiatric Press have compiled a CD-ROM containing the full text of 10 psychiatric journals and 14 major psychiatric textbooks. Ovid's Core Biomedical Collections (volumes I, II and III) each contain 15 international journals with full text and graphics compiled from 1993 to date. A total of approximately 40000 articles. One psychiatric journal is included in each volume. In the future Ovid expects to offer a collection devoted to mental health. New from Elsevier is Bio-Psychiatry on CD-ROM. This is a full text version of three journals: Biological Psychiatry. Neuropsychopharmacology and Schizophrenia Research. At US\$195 it is considerably cheaper than a subscription to the journals themselves! Rapid Science produce Current Opinion in Psychiatry on CD-ROM, a full text and graphic database for all review articles from the journal since 1994. Rapid Science also offer a ten year archive of psychiatric abstracts on CDROM called Psychiatry Evaluated Medline. It offers no additional material beyond Medline, but is an inexpensive alternative for those interested in an overview of psychiatry alone. SilverPlatter have introduced a very similar product known as Physicians' SilverPlatter: Psychiatry. It is sourced from 205 speciality journals over a five-year period and again appears to offer no advantages over Medline.

A comparison of the CD-ROMs in psychiatry is listed in Table 1 and Figure 1 outlines which psychiatric database to use on CD-ROM.

\section{Current awareness services}

One problem with distributed databases is that the latest literature is not included. Current awareness services attempt to offer a solution by circulating regular abstracts of current articles of interest. The Royal Society of Medicine produce a current medical literature series in specialities ranging from 'Allergy' to 'Virology'. The quarterly psychiatric issue is indexed from 78 key journals. The Institute of Scientific Information produce the more substantial Focus On Series, including Focus On: Psychopharmacology which is distributed on diskette monthly and edited by authorities in the field of biological

Table 1. Comparison of CD-ROMs in psychiatry

\begin{tabular}{|c|c|c|c|c|c|c|c|}
\hline Database & Coverage & & & Size & & Cost & \\
\hline & Subject & Year & $\begin{array}{l}\text { Joumal } \\
\text { and } \\
\text { cltation }\end{array}$ & $\begin{array}{l}\text { Number } \\
\text { of disks }\end{array}$ & Clitations & 'Total' & $\begin{array}{l}\text { Per } \\
\text { reference }\end{array}$ \\
\hline Medline & Biomedicine & $1966-1996$ & $\begin{array}{l}3800 \\
\text { Abstracts }\end{array}$ & 10 & 8000000 & $£ 1560$ & $0.02 p$ \\
\hline Embase Psychiatry & Psychiatry & $1986-1995$ & $\begin{array}{l}3500 \\
\text { Abstracts }\end{array}$ & 1 & 303000 & $£ 750$ & $0.25 p$ \\
\hline Psyclit & Psychology & $1984-1995$ & $\begin{array}{l}1300 \\
\text { Abstracts }\end{array}$ & 1 & 730000 & $£ 2435$ & $0.33 p$ \\
\hline ClinPSYC & Psychology & $1980-1996$ & $\begin{array}{l}1300 \\
\text { Abstracts }\end{array}$ & 1 & 280000 & $£ 1560$ & $0.55 p$ \\
\hline $\begin{array}{l}\text { American Psychiatric } \\
\text { Electronic Library }\end{array}$ & Psychiatry & $1992-1996$ & $\begin{array}{c}11 \\
\text { Full text }\end{array}$ & 2 & NA & US\$795 & NA \\
\hline $\begin{array}{l}\text { OVID Core Collection } \\
\text { Volume } 1 / 11 / I I\end{array}$ & Biomedicine & $1993-1996$ & $\begin{array}{l}15 \\
\text { Full text }\end{array}$ & 13 & NA & $£ 2500$ & NA \\
\hline Blo-Psychiatry & Psychiatry & $1993-1996$ & $\begin{array}{c}3 \\
\text { Full text }\end{array}$ & 1 & NA & US\$195 & NA \\
\hline Physicians' Silver Platter & Psychiatry & $1992-1996$ & $\begin{array}{l}205 \\
\text { Abstracts }\end{array}$ & 1 & 175000 & $£ 359$ & $0.21 p$ \\
\hline Neuroscience Citation & Neurobiology & $1991-1996$ & $\begin{array}{l}2800 \\
\text { Abstracts }\end{array}$ & 1 & $\begin{array}{l}75000 \\
\text { per year }\end{array}$ & US\$1530 & $1.3 p$ \\
\hline $\begin{array}{l}\text { Current Opinion in } \\
\text { Psychiatry on CD-ROM }\end{array}$ & Psychiatry & $1994-1996$ & $\begin{array}{c}1 \\
\text { Full text }\end{array}$ & 1 & NA & $\$ 195$ & NA \\
\hline $\begin{array}{l}\text { Psychiatry Evaluated } \\
\text { Medline }\end{array}$ & Psychiatry & $1982-1991$ & $\begin{array}{l}100 \\
\text { Abstracts }\end{array}$ & 1 & Unknown & $\$ 120$ & Unknown \\
\hline
\end{tabular}

'Single user cost as of March 1997, costs for institutions/multiple copies may vary. 


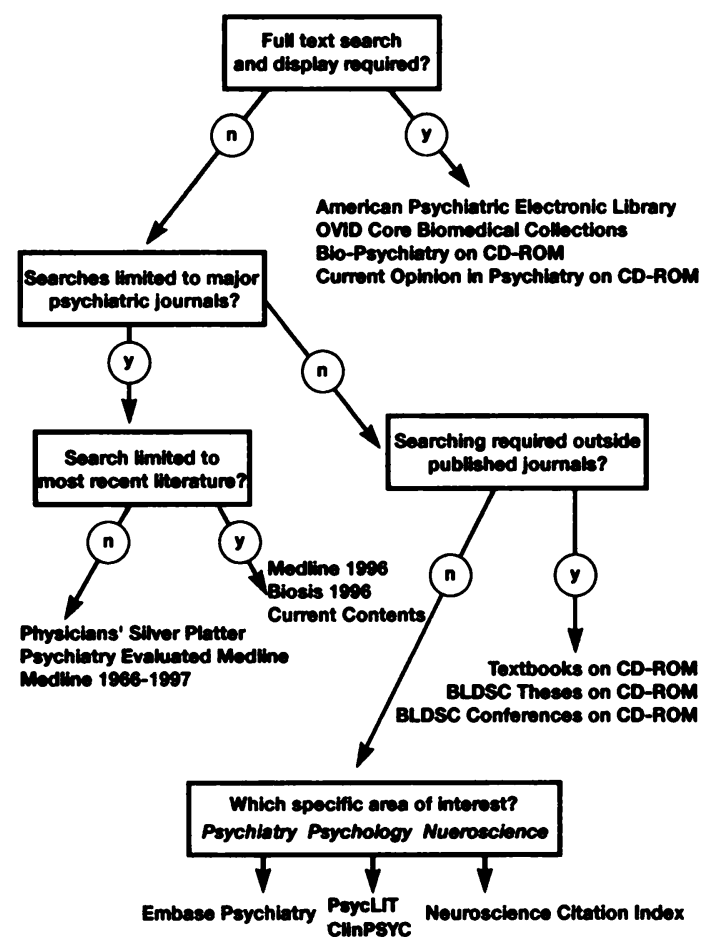

Figure 1. Which psychiatric database to use on CD-ROM?

psychiatry. Elsevier Science offer a similar subscription service known as Current Advances in Neuroscience. Both products are available on Windows and Macintosh formats and are priced around £200. Free alternatives appear from time-to-time, sponsored by pharmaceutical companies. In general, these are of poor quality and their circulation is unreliable.

\section{Conclusions}

CD-ROMs enforce an inherent delay between article publication and availability. Publication on-line overcomes this (Ohles \& Walton, 1996). Already, several journals reside solely on the internet and literature search facilities are also increasing (Huang \& Alessi, 1996). BIDS databases are never more than a week out of date. Ovid and SilverPlatter both have web sites on the internet, and these and other sites allow on-line access to several CD-ROMs (Elameer, 1993). At present, the high costs of electronic databases limit the average user to one or two carefully selected products. The commonest mistake of clinicians examining the literature is to assume that all work published is listed in Medline. This is far from the case. These tools facilitate the rapid selection of relevant material but ultimately old-fashioned hand searching is necessary to confirm the reference, critically read the original report and to obtain further author cited work. Many pieces of interesting work never make it onto CD-ROM therefore online data and grey-literature should not be overlooked (Dickersin \& Min, 1993). In addition older publications are often available only as originals. Finally the ability of any tool to reveal its information is ultimately governed by the user (Adams et al, 1994) and for this reason whichever bibliographic database one chooses it must be mastered.

\section{Acknowledgements}

Thanks to Ovid Technologies, the Institute of Scientific Information and SilverPlatter Ltd for their assistance.

\section{References}

Adams, C. E., Power, A., Frederick, K., et al (1994) An investigation of the adequacy of MEDLINE searches for randomized controlled trials (RCTs) of the effects of mental health care. Psychological Medicine. 24. 741749.

Dickersin. K. \& MiN. Y. I. (1993) Publication bias: the problem that won't go away. Annals of the New York Academy of Science. 703, 135-148.

ElameER, M. S. (1993) Literature search from home. Psychiatric Bulletin, 17, 554-555.

HuANG, M. P. \& ALESSI, N. E. (1996) The Internet and the future of psychiatry. American Journal of Psychiatry. 163. 861-869.

OHLES, J. A. \& WALTON, L. (1996) The Internet: a valuable resource for the hospital librarian. Bulletin of the Medical Library Association, 84, 110-111.

WAKEFORD, R. \& ROBERTS, W. (1993) Using Medline for comprehensive searches. British Medical Journal, $\mathbf{3 0 6}$. 1415.

*Alexander Mitchell, Senior House Officer in Psychiatry, Addenbrooke's Hospital, Cambridge; alex mitchell@dialpipex.com and Ian Preston. Librarian, Fulbourn Library, Cambridge CB1 5EF, and Clare Martin, Assistant Librarian. Institute of Psychiatry, Denmark Hill, London SE5 8AF

*Correspondence 